\title{
SUPERVISI AKADEMIK BENTUK TSUBASA METER UNTUK MENINGKATKAN KOMPETENSI PROFESIONAL GURU
}

\author{
Srikah
}

\author{
Guru SDN Wonodadi I, Kec. Kutorejo Kab. Mojokerto \\ Email: dewisri-wedari@yahoo.com
}

\begin{tabular}{l}
\hline Tersedia Online di \\
\hline http://www.jurnal.unublitar.ac.id/i \\
ndex.php/briliant
\end{tabular}

Sejarah Artikel

Diterima pada 2 Januari 2017

Disetuji pada 20 Januari 2017

Dipublikasikan pada 1 Februari

2017 Hal. 32 - 42

\section{Kata Kunci:}

Supervise akademik, tsubasa meter, profesionalisme guru

\begin{abstract}
Abstrak: Berdasarkan supervisi kelas, proses pembelajaran matematika didapatkan bahwa dalam menyusun rencana pembelajaran dan pelaksanaan masih rendah. Jenis penelitian ini adalah Penelitian Tindakan Sekolah (PTS) dengan 2 siklus. Subjek pada penelitian ini adalah guru matematika dan siswa kelas IV SDN Wonodadi-1 Kutorejo Mojokerto yang berjumlah 23 siswa. Metode pengumpulan data yaitu observasi dan tes. Instrumen yang digunakan adalah lembar observasi penyusunan RPP, lembar observasi pelaksanaan pembelajaran dan lembar tes hasil belajar. Berdasarkan hasil penelitian diperoleh hasil bahwa melalui supervisi akademik dengan penerapan media Tsubasa Meter pada materi satuan panjang meningkatkan profesionalisme guru dan hasil belajar siswa.
\end{abstract}

Hakikat pendidikan mencakup kegiatan mendidik, mengajar, dan melatih. Kegiatan tersebut kita laksanakan sebagai suatu usaha untuk mentransformasi nilai-nilai. Maka dalam pelaksanaannya ketiga kegiatan tadi harus berjalan secara serempak dan terpadu, dan berkelanjutan, serta serasi dengan perkembangan anak didik serta lingkungan hidupnya. (Lamijan, dkk,2007:9)

Komponen pendidikan yang cukup berperan dalam memajukan mutu pendidikan adalah guru. Hal ini disebabkan karena guru memegang peran penting dalam proses pembelajaran yang berlangsung di sekolahan atau di kelas. Untuk itu seorang guru diharapkan memiliki kemampuan professional yang tinggi misalnya guru wajib mengenal siswa-siswanya dengan baik, guru perlu memiliki kemampuan untuk melakukan diagnosis serta mengenal dengan baik cara-cara paling efektif untuk membantu siswa agar tumbuh sesuai dengan potensinya masing-masing. Sebagaimana dikatakan Combs, tugas utama guru adalah bertanggung jawab membantu anak didik dalam hal belajar. Dalam proses belajar mengajar, gurulah yang menyampaikan pelajaran, memecahkan masalah-masalah yang terjadi dalam kelas, membuat evaluasi belajar siswa, baik sebelum, sedang maupun sesudah pelajaran berlangsung (Combs, 1984:11-13). 
Salah satu pelajaran atau materi ajar yang cukup berperan dalam kehidupan sehari-hari adalah pelajaran matematika. Hal ini disebabkan karena matematika dapat meningkatkan pengetahuan siswa dalam berpikir secara logis, rasional, kritis dan cermat. Tetapi fakta yang ada dilapangan matematika adalah mata pelajaran yang dianggap sulit oleh siswa. Banyak siswa tidak memahami konsep dasar dari materi tersebut, sehingga siswa merasa kesulitan dalam mempelajari matematika. Sehingga banyak siswa kurang aktif dalam pembelajaran.

Guru juga memegang peran sentral dalam pembelajaran selain siswa yang belajar. Oleh karena itu metode mengajar berperan sebagai alat untuk menciptakan proses mengajar dan belajar. Metode ini diharapkan dapat menumbuhkan berbagai kegiatan belajar siswa sehubungan dengan mengajar guru sehingga terciptalah interaksi edukatif. Interaksi edukatif adalah interaksi dimana guru berperan sebagai penggerak / pembimbing, sedangkan siswa berperan sebagai penerima / yang dibimbing. Proses interaksi ini akan berjalan baik kalau siswa banyak aktif dibandingkan dengan guru. Oleh karenanya metode mengajar yang baik adalah metode yang menumbuhkan kegiatan belajar siswa (Sudjana, Nana, 2010: 76).

Untuk bisa menggunakan metode mengajar yang baik maka seorang guru harus melakukan persiapan-persiapan yang baik. Persiapan itu meliputi perencanaan, pelaksanaan dan refleksi pembelajaran. Sehingga guru sebelum melaksanakan pembelajaran guru wajib merancang Rencana Pelaksanaan Pembelajaran (RPP). Pembuatan RPP ini dimaksudkan agar guru mengetahui materi apa yang akan disampaikan, kopetensi apa yang harus dikuasai siswa setelah pembelajaran selesai. Guru juga harus menetapkan model atau straegi pembelajaran apa yang sesuai dengan karakteristik materi.

Penelitian ini berawal dari kondisi hasil supervisi di SDN Wonodadi-1 kelas IV Kutorejo Mojoerto pada guru matematika. Supervisi yang dilakukan peneliti adalah pengamatan RPP dan pelaksanaan pembelajaran. Berdasarkan hasil supervisi dalam penyususnaan RPP didapatkan bahwa: pemilihan media dan pengorganisasian materi perlu diperhatikan, juga kelengkaapan instrumen dilengkapi sesuaikan karakteristik materi dengan media maupun strategi pembelajarannya. Sedangkan dalam pelaksanaan pembelajaran didapat bahwa : guru kurang melaksanakan pembelajaran sesuai dengetan metode yang direncanakan, kurang menumbuhkan partisipasi aktif siswa dalam pembelajaran, guru tidak melakukan refleksi atau membuat rangkuman dengan melibatkan siswa, guru tidak melaksanakan tindak lanjut dengan memberikan arahan, atau kegiatan, atau tugas sebagai bagian remidi/pengayaan.

Hal ini berdampak pada rendahnya hasil belajar matematika siswa kelas IV karena masih banyak yang belum memenuhi KKM (KKM $\geq 75)$. Jumlah siswa yang belum memenuhi KKM sebanyak 12 siswa $(52,18 \%)$ dan yang memenuhi KKM sebanyak 11 siswa $(47,82 \%)$ dari sejumlah siswa sebanyak 23 siswa. Sedangkan KKM secara klasikal yang ditetapkan sebesar $80 \%$ ini menunjukkan bahwa hasil belajar belum memenuhi Ketuntasan secara klasikal.

Agar pembelajaran lebih menyenangkan bisa tercapai, peneliti berasumsi bahwa guru akan baik dalam melaksanakan tugasnya jika ada kontrol yang 
konsisten, berkesinambungan dari Pengawas Sekolah. Apabila volume supervisi Pengawas ditingkatkan, maka kinerja guru menjadi lebih baik. Upaya yang dapat dilakukan untuk meningkatkan kinerja guru dalam pembelajaran matematika pada materi Satuan Panjang adalah memperbaiki RPP dan pelaksanaan pembelajarn sehingga mampu melibatkan siswa secara aktif baik fisik, emosi, maupun sosial.

Berdasarkan hal tersebut, maka peneliti perlu menerapan supervisi akademik untuk meningkatkan profesional guru matematika Wonodadi 1 Kutorejo Mojokerto pada materi satuan panjang melalui media media tsubasa meter.

Penggunaan media pembelajaran sangat penting untuk meningkatkan minat belajar siswa. Maka dari itu saat ini guru dituntut untuk lebih kreatif dan tidak lagi hanya menggunakan sistem pembelajaran yang konvensional atau hanya menggunakan lembar kerja siswa dan buku-buku cetak lainnya. Hal ini menyebabkan proses pembelajaran hanya membuat siswa cepat bosan. Dengan menggunakan media pembelajaran siswa akan lebih aktif lagi dalam proses belajar mengajar. Tsubasa Meter (Trik singkat ubah satuan meter) adalah media yang dapat mempermudah siswa dalam megkonversi satuan panjang. Media ini terbuat dari papan milamin (triplek). Pada papan melamin dibuat bingkai dengan berbagai gambar yang menarik. Kemudian dibuat sketsa judul dan kolom pada papan melamin kemudian ditebali dengan boardmarker.

Dengan mengunakan media pembelajaran dalam proses pembelajaran akan mendapatkan keistimewaan dalam proses pembelajaran. Menurut Gerlac (dalam Ulfa,2013) ditegaskan bahwa ada tiga keistemewaan yang dimiliki media pembelajaran yaitu: (1) media memiliki kemampuan untuk menangkap, menyimpan, dan menampilkan kembali suatu objek atau kejadian; (2) media memiliki kemampuan untuk menampilkan kembali objek atau kejadian dengan berbagai macam cara disesuaikan dengan keperluan; dan (3) media mempunyai kemampuan utuk menampilkan sesuatu objek atau kejadian yang mengandung makna.

\section{METODE}

Jenis penelitian ini merupakan Penelitian Tindakan Sekolah (PTS) dengan menggunakan metode deskriptif kualitatif. Metode deskriptif adalah metode yang hakikatnya berdasarkan fakta dengan tujuan melukiskan kenyataan sebenarnya dari suatu obyek. Penelitian kualitatif menurut bagdan dan taylor prosedur penelitian yang menghasilkan data deskriptif berupa kata-kata tertulis atau lisan dari perilaku yang diamati. (Moleong,2007: 4). Adapaun tujuan utama PTS adalah untuk meningkatkan kualitas pembelajaran bukan untuk menghasilkan pengetahuan. Peningkatan kualitas pembelajaran bisa mencakup bagaimana guru dalam menyusun RPP dan bagaimana pelaksanaan pembelajaran dikelas.

\section{Subjek Penelitian}

Penelitian ini akan dilaksanakan di kelas IV SDN Wonodadi-1 Kecamatan Kutorejo Kabupaten Mojokerto Semester I tahun pelajaran 2016 2017. Dalam penelitian ini yang menjadi subjek penelitian adalah Guru dan siswa kelas IV SDN Wonodadi 1 Kutorejo Mojokerto, sebagai praktikan guru 
matematika kelas IV Kutorejo 1 dan peneliti dengan teman sejawat sebagai observer.

\section{Waktu Penelitian}

Penelitian dilaksanakan selama 4 bulan yaitu September 2016 sampai dengan Desember 2016, terdiri dari 2 siklus. Siklus I pada tanggal 7 dan 14 Oktober 2016 dengan kegiatan melaksanakan pendampingan dlm. proses pembelajaran, sekaligus melaksanakan tugas observasi kelas. Sedangkan siklus II pada tanggal 4 dan 11 November 2016 dengan kegiatan yang sama seperti pada siklus I.

\section{Instrumen Penelitian}

\section{Lembar Observasi}

Observasi adalah kegiatan pengamatan untuk memotret seberapa jauh efek tindakan telah mencapai sasaran. Lembar ofservasi ada 2 yaitu observasi untuk Rencana Pelaksanaan Pembelajaran dan Pelaksanaan Pembelajaran.

\section{Tes}

Tes adalah serentetan pertanyaan atau latihan serta alat lain yang digunakan untuk mengukur keterampilan, pengetahuan inteligensi, kemampuan atau bakat yang dimiliki oleh individu atau kelompok. Arikunto (2013:193). Tes yang digunakan pada penelitian ini adalah tes subjektif berbentuk essay dan diberikan sesudah dilaksanakan kegiatan pembelajaran dengan menggunakan media Tsubasa Meter.

\section{Metode Pengumpulan Data Observasi}

Observasi dilakukan untuk mengamati siswa selama proses pembelajaran dengan menggunakan media Tsubasa Meter. Pada tahap ini peneliti melakukan observasi dengan menggunakan lembar observasi/pengamatan yang telah disiapkan. Metode observasi digunakan untuk mengungkapkan data aktivitas siswa selama pembelajaran berlangsung.

\section{Tes}

Metode tes digunakan untuk memperoleh data hasil belajar siswa selama proses pembelajaran. Tes dilakukan pada akhir kegiatan pembelajaran untuk mengetahui atau mengukur hasil belajar siswa setelah memperoleh pembelajaran dengan menggunakan media stubasa meter.

\section{Teknik Analisis Data}

Analisis Rencana Pelaksanaan Pembelajaran (RPP), Pelaksanaan Pembelajaran dapat dihitung dengan rumus: Rata-rata nilai RPP atau rata-rata pembelajaran jumlah skor yang diperoleh/skor total. Analisis data tes hasil belajar rata-rata hasil belajar peserta didik dengan rumus nilai rata-rata peserta didik $=$ jumlah semua nilai peserta didik/banyaknya peserta didik dalam satu kelas. 
Hasil

Siklus I

Hasil observasi pada penyusunan RPP dengan instrumen F.RPP : dari data F. RPP bahwa profesionalisme guru dalam merancang RPP skor rata-rata 3,25 masih dalam kategori cukup baik. Sedangkan hasil observasi F. PBM dengan skor rata-rata 3,33 dengan kriteria cukup baik. Hasil supervisi disajikan pada tabel 1 dan tabel 2 .

Tabel 1 Hasil Supervisi Penyusunan Pembelajaran Siklus I

\begin{tabular}{|c|l|c|}
\hline No & \multicolumn{1}{|c|}{ Aspek yang dinilai } & Skor \\
\hline 1. & $\begin{array}{l}\text { Kejelasan perumusan tujuan pembelajaran (tidak menimbulkan } \\
\text { penafsiran ganda dan mengandung perilaku hasil belajar) }\end{array}$ & 4 \\
\hline 2. & $\begin{array}{l}\text { Pemilihan materi ajar (sesuai dengan tujuan dan karakteristik } \\
\text { peserta didik) }\end{array}$ & 4 \\
\hline 3. & $\begin{array}{l}\text { Pengorganisasian materi ajar (keruntutan, sistematika materi } \\
\text { dan } \\
\text { kesesuaian dengan alokasi waktu) }\end{array}$ & 3 \\
\hline 4. & $\begin{array}{l}\text { Pemilihan sumber/media pembelajaran (sesuai dengan tujuan, } \\
\text { materi, dan karakteristik peserta didik) }\end{array}$ & 3 \\
\hline 5. & $\begin{array}{l}\text { Kejelasan skenario pembelajaran (langkah-langkah kegiatan } \\
\text { pembelajaran : awal, inti, dan penutup) }\end{array}$ & 3 \\
\hline 6. & $\begin{array}{l}\text { Kerincian skenario pembelajaran (setiap langkah tercermin } \\
\text { strategi / metode dan alokasi waktu pada setiap tahap) }\end{array}$ & 3 \\
\hline 7. & Kesesuaian teknik dengan tujuan pembelajaran & 3 \\
\hline 8. & Kekengkapan instrumen (soal, kunci, pedoman penskoran) & $\mathbf{2 6}$ \\
\hline & Skor total & $\mathbf{3 , 2 5}$ \\
\hline & Rata - Rata \\
\hline
\end{tabular}

Petunjuk Skor $1=$ Kurang sekali , $2=$ Kurang, $3=$ Cukup, $4=$ baik, $5=$ baik sekali

Tabel 2 Hasil Observasi Pelaksanaan Pembelajaran siklus I

\begin{tabular}{|l|l|c|}
\hline NO & INDIKATOR/ASPEK YANG DIAMATI & SKOR \\
\hline I & PRAPEMBELAJARAN & \\
\hline 1. & Memeriksa kesiapan siswa & 4 \\
\hline 2. & Melakukan kegiatan apersepsi & 4 \\
\hline II & KEGIATAN INTI PEMBELAJARAN & \\
\hline A. & Penguasaan materi pelajaran & 3 \\
\hline 3. & Menunjukkan penguasaan materi pembelajaran & 4 \\
\hline 4. & Mengaitkan materi dengan pengetahuan lain yang relevan & 4 \\
\hline 5. & $\begin{array}{l}\text { Menyampaikan materi dengan jelas dan sesuai dengan } \\
\text { hierarki belajar }\end{array}$ & 3 \\
\hline 6. & Mengaitkan materi dengan realitas kehidupan & \\
\hline B. & Pendekatan/strategi/ Metode pembelajaran & \\
\hline
\end{tabular}

36 BRILLIANT: Jurnal Riset dan Konseptual Volume 2 Nomor 1, Februari 2017 


\begin{tabular}{|c|c|c|}
\hline NO & INDIKATOR/ASPEK YANG DIAMATI & SKOR \\
\hline 7 & $\begin{array}{l}\text { Melaksanakan pembelajaran sesuai dengan kompetensi } \\
\text { (tujuan) yang akan dicapai }\end{array}$ & 3 \\
\hline 8 & $\begin{array}{l}\text { Melaksanakan pembelajaran secara runtut sesuai dengan } \\
\text { metode yang digunakan }\end{array}$ & 3 \\
\hline 9 & $\begin{array}{l}\text { Melaksanakan pembelajaran sesuai dengetan metode yang } \\
\text { direncanakan }\end{array}$ & 3 \\
\hline 10 & Melaksanakan pembelajaran yang bersifat kontekstual & 3 \\
\hline 11 & $\begin{array}{l}\text { Melaksanakan pembelajaran yang memungkinkan } \\
\text { tumbuhnya kebiasaan positif }\end{array}$ & 3 \\
\hline 12 & $\begin{array}{l}\text { Melaksanakan pembelajaran sesuai dengan alokasi waktu } \\
\text { yang direncanakan }\end{array}$ & 3 \\
\hline C. & Pemanfaatan sumber belajar /media pembelajaran & \\
\hline 13. & Menggunakan media secara efektif dan efisien & 3 \\
\hline 14. & Menghasilkan pesan yang menarik & 3 \\
\hline 15. & Melibatkan siswa dalam pemanfaatan media & 3 \\
\hline D. & $\begin{array}{l}\text { Pembelajaran yang memicu dan memelihara keterlibatan } \\
\text { siswa }\end{array}$ & \\
\hline 16. & Menumbuhkan partisipasi aktif siswa dalam pembelajaran & 3 \\
\hline 17. & Menunjukkan sikap terbuka terhadap respons siswa & 4 \\
\hline 18. & Menumbuhkan keceriaan dan antusisme siswa dalam belajar & 3 \\
\hline E. & Penilaian proses dan hasil belajar & \\
\hline 19. & Memantau kemajuan belajar selama proses & 3 \\
\hline 20. & $\begin{array}{l}\text { Melakukan penilaian akhir sesuai dengan kompetensi } \\
\text { (tujuan) }\end{array}$ & 3 \\
\hline F. & Penggunaan bahasa & \\
\hline 21. & $\begin{array}{l}\text { Menggunakan bahasa lisan dan tulis secara jelas, baik, dan } \\
\text { benar }\end{array}$ & 4 \\
\hline 22. & Menyampaikan pesan dengan gaya yang sesuai & 3 \\
\hline III & PENUTUP & \\
\hline 23. & $\begin{array}{l}\text { Melakukan refleksi atau membuat rangkuman dengan } \\
\text { melibatkan siswa }\end{array}$ & 4 \\
\hline \multirow[t]{3}{*}{24.} & $\begin{array}{l}\text { Melaksanakan tindak lanjut dengan memberikan arahan, } \\
\text { atau kegiatan, atau tugas sebagai bagian remidi/pengayaan }\end{array}$ & 4 \\
\hline & Total Skor & 80 \\
\hline & Rata-rata & 3,33 \\
\hline
\end{tabular}

Rata-rata skor menyusun RPP dan pelaksanaan pembelajaran peneliti sajikan pada Tabel 3.

Tabel 4 Rata-rata Skor

\begin{tabular}{|l|l|c|c|}
\hline No & Nama Guru & F. RPP. 1 & F.PBM.1 \\
\hline 1 & Wanari, S.Pd & $\mathbf{3 , 2 5}$ & $\mathbf{3 , 3 3}$ \\
\hline & Rata-rata & \multicolumn{2}{|c|}{$\mathbf{3 , 2 9}$} \\
\hline
\end{tabular}




\section{Siklus II}

Hasil observasi pada penyusunan RPP dengan instrumen F.RPP : dari data F. RPP bahwa profesionalisme guru dalam merancang RPP skor rata-rata 3,25 masih dalam kategori cukup baik. Sedangkan hasil observasi F. PBM dengan skor rata-rata 3,33 dengan kriteria cukup baik. Hasil supervisi akademik peneliti sajikan pada tabel 4 dan tabel 5 :

\section{Tabel 4 Hasil Supervisi Penyusunan Pembelajaran Siklus II}

\begin{tabular}{|c|l|c|}
\hline No & Aspek yang dinilai & Skor \\
\hline 1. & $\begin{array}{l}\text { Kejelasan perumusan tujuan pembelajaran (tidak menimbulkan } \\
\text { penafsiran ganda dan mengandung perilaku hasil belajar) }\end{array}$ & 4 \\
\hline 2. & $\begin{array}{l}\text { Pemilihan materi ajar (sesuai dengan tujuan dan karakteristik } \\
\text { peserta didik) }\end{array}$ & 4 \\
\hline 3. & $\begin{array}{l}\text { Pengorganisasian materi ajar (keruntutan, sistematika materi } \\
\text { dan } \\
\text { kesesuaian dengan alokasi waktu) }\end{array}$ & 3 \\
\hline 4. & $\begin{array}{l}\text { Pemilihan sumber/media pembelajaran (sesuai dengan tujuan, } \\
\text { materi, dan karakteristik peserta didik) }\end{array}$ & 3 \\
\hline 5. & $\begin{array}{l}\text { Kejelasan skenario pembelajaran (langkah-langkah kegiatan } \\
\text { pembelajaran : awal, inti, dan penutup) }\end{array}$ & 3 \\
\hline 6. & $\begin{array}{l}\text { Kerincian skenario pembelajaran (setiap langkah tercermin } \\
\text { strategi / metode dan alokasi waktu pada setiap tahap) }\end{array}$ & 4 \\
\hline 7. & Kesesuaian teknik dengan tujuan pembelajaran & 4 \\
\hline 8. & Kekengkapan instrumen (soal, kunci, pedoman penskoran) & $\mathbf{2 9}$ \\
\hline \multicolumn{2}{|c|}{ Skor total } & $\mathbf{3 , 6 3}$ \\
\hline
\end{tabular}

Tabel 5 Hasil Observasi Pelaksanaan Pembelajaran siklus I

\begin{tabular}{|l|l|c|}
\hline NO & INDIKATOR/ASPEK YANG DIAMATI & SKOR \\
\hline I & PRAPEMBELAJARAN & \\
\hline 1. & Memeriksa kesiapan siswa & 4 \\
\hline 2. & Melakukan kegiatan apersepsi & \\
\hline II & KEGIATAN INTI PEMBELAJARAN & \\
\hline A. & Penguasaan materi pelajaran & 4 \\
\hline 3. & Menunjukkan penguasaan materi pembelajaran & 4 \\
\hline 4. & Mengaitkan materi dengan pengetahuan lain yang relevan & 4 \\
\hline 5. & $\begin{array}{l}\text { Menyampaikan materi dengan jelas dan sesuai dengan } \\
\text { hierarki belajar }\end{array}$ & 4 \\
\hline 6. & Mengaitkan materi dengan realitas kehidupan & 4 \\
\hline B. & Pendekatan/strategi/ Metode pembelajaran & 4 \\
\hline 7 & $\begin{array}{l}\text { Melaksanakan pembelajaran sesuai dengan kompetensi } \\
\text { (tujuan) yang akan dicapai }\end{array}$ & \\
\hline 8 & Melaksanakan pembelajaran secara runtut sesuai dengan & 4 \\
\hline
\end{tabular}

38 BRILLIANT: Jurnal Riset dan Konseptual Volume 2 Nomor 1, Februari 2017 


\begin{tabular}{|c|c|c|}
\hline NO & INDIKATOR/ASPEK YANG DIAMATI & SKOR \\
\hline & metode yang digunakan & \\
\hline 9 & $\begin{array}{l}\text { Melaksanakan pembelajaran sesuai dengetan metode yang } \\
\text { direncanakan }\end{array}$ & 5 \\
\hline 10 & Melaksanakan pembelajaran yang bersifat kontekstual & 5 \\
\hline 11 & $\begin{array}{l}\text { Melaksanakan pembelajaran yang memungkinkan } \\
\text { tumbuhnya kebiasaan positif }\end{array}$ & 4 \\
\hline 12 & $\begin{array}{l}\text { Melaksanakan pembelajaran sesuai dengan alokasi waktu } \\
\text { yang direncanakan }\end{array}$ & 4 \\
\hline C. & Pemanfaatan sumber belajar /media pembelajaran & \\
\hline 13. & Menggunakan media secara efektif dan efisien & 4 \\
\hline 14. & Menghasilkan pesan yang menarik & 3 \\
\hline 15. & Melibatkan siswa dalam pemanfaatan media & 4 \\
\hline D. & $\begin{array}{l}\text { Pembelajaran yang memicu dan memelihara keterlibatan } \\
\text { siswa }\end{array}$ & 4 \\
\hline 16. & Menumbuhkan partisipasi aktif siswa dalam pembelajaran & 4 \\
\hline 17. & Menunjukkan sikap terbuka terhadap respons siswa & 4 \\
\hline 18. & Menumbuhkan keceriaan dan antusisme siswa dalam belajar & 3 \\
\hline E. & Penilaian proses dan hasil belajar & \\
\hline 19. & Memantau kemajuan belajar selama proses & 4 \\
\hline 20. & $\begin{array}{l}\text { Melakukan penilaian akhir sesuai dengan kompetensi } \\
\text { (tujuan) }\end{array}$ & 4 \\
\hline F. & Penggunaan bahasa & \\
\hline 21. & $\begin{array}{l}\text { Menggunakan bahasa lisan dan tulis secara jelas, baik, dan } \\
\text { benar }\end{array}$ & 3 \\
\hline 22. & Menyampaikan pesan dengan gaya yang sesuai & 5 \\
\hline III & PENUTUP & \\
\hline \multirow[t]{3}{*}{23.} & $\begin{array}{l}\text { Melakukan refleksi atau membuat rangkuman dengan } \\
\text { melibatkan siswa }\end{array}$ & 5 \\
\hline & Total Skor & 97 \\
\hline & Rata-rata & 4,04 \\
\hline
\end{tabular}

Rata-rata skor menyusun RPP dan pelaksanaan pembelajaran peneliti sajikan pada tabel 6 .

Tabel 6 Rata-rata Skor

\begin{tabular}{|l|l|c|c|}
\hline No & Nama Guru & F. RPP. 1 & F.PBM.1 \\
\hline 1 & Wanari, S.Pd. & $\mathbf{3 , 6 3}$ & $\mathbf{4 , 0 4}$ \\
\hline & Rata-rata & \multicolumn{2}{|c|}{$\mathbf{3 , 8 4}$} \\
\hline
\end{tabular}




\section{Hasil Belajar}

Data hasil belajar peneliti sajikan pada Siklus I peneliti sajikan tabel 7

Tabel 7. Hasil Tes Siklus I

\begin{tabular}{|c|c|c|c|}
\hline No & Nama & Hasil Tes I & Keterangan \\
\hline 1 & $\mathrm{ABA}$ & 70 & Belum Tuntas \\
\hline 2 & $\mathrm{ADF}$ & 85 & Tuntas \\
\hline 3 & ANP & 70 & Belum Tuntas \\
\hline 4 & BPS & 85 & Tuntas \\
\hline 5 & CND & 65 & Belum Tuntas \\
\hline 6 & GAP & 90 & Tuntas \\
\hline 7 & IFN & 75 & Tuntas \\
\hline 8 & RWL & 70 & Belum Tuntas \\
\hline 9 & IVS & 65 & Belum Tuntas \\
\hline 10 & MAA & 80 & Tuntas \\
\hline 11 & MFA & 65 & Belum Tuntas \\
\hline 12 & MRA & 85 & Tuntas \\
\hline 13 & NAH & 55 & Belum Tuntas \\
\hline 14 & NER & 85 & Tuntas \\
\hline 15 & RAS & 65 & Belum Tuntas \\
\hline 16 & RNT & 70 & Belum Tuntas \\
\hline 17 & SYK & 80 & Tuntas \\
\hline 18 & TIS & 70 & Belum Tuntas \\
\hline 19 & TRH & 55 & Belum Tuntas \\
\hline 20 & TSM & 85 & Tuntas \\
\hline 21 & VAZ & 65 & Belum Tuntas \\
\hline 22 & VAW & 70 & Belum Tuntas \\
\hline 23 & WSF & 65 & Belum Tuntas \\
\hline \multicolumn{2}{|c|}{ Jumlah } & 1670 & \\
\hline \multicolumn{2}{|c|}{ Rata - rata } & 72,61 & \\
\hline
\end{tabular}

Berdasarkan Tabel 7 terlihat bahwa rata-rata hasil belajar siswa pada materi satuan panjang adalah 72,61 termasuk cukup dengan KKM secara klasikal sebesar $14 / 23=60,86 \%$. 
Data hasil belajar peneliti sajikan pada Siklus I peneliti sajikan tabel 8

Tabel 8. Hasil Tes Siklus II

\begin{tabular}{|c|c|c|c|}
\hline No & Nama & Hasil Tes II & Keterangan \\
\hline 1 & $\mathrm{ABA}$ & 75 & Tuntas \\
\hline 2 & $\mathrm{ADF}$ & 85 & Tuntas \\
\hline 3 & ANP & 85 & Tuntas \\
\hline 4 & BPS & 95 & Tuntas \\
\hline 5 & CND & 65 & Belum Tuntas \\
\hline 6 & GAP & 85 & Tuntas \\
\hline 7 & IFN & 75 & Tuntas \\
\hline 8 & RWL & 85 & Tuntas \\
\hline 9 & IVS & 70 & Belum Tuntas \\
\hline 10 & MAA & 85 & Tuntas \\
\hline 11 & MFA & 65 & Tuntas \\
\hline 12 & MRA & 85 & Tuntas \\
\hline 13 & NAH & 75 & Tuntas \\
\hline 14 & NER & 90 & Tuntas \\
\hline 15 & RAS & 70 & Belum Tuntas \\
\hline 16 & RNT & 65 & Belum Tuntas \\
\hline 17 & SYK & 90 & Tuntas \\
\hline 18 & TIS & 70 & Belum Tuntas \\
\hline 19 & TRH & 65 & Belum Tuntas \\
\hline 20 & TSM & 95 & Tuntas \\
\hline 21 & VAZ & 70 & Belum Tuntas \\
\hline 22 & VAW & 80 & Tuntas \\
\hline 23 & WSF & 65 & Belum Tuntas \\
\hline \multicolumn{2}{|c|}{ Jumlah } & 1790 & \\
\hline \multicolumn{2}{|c|}{ Rata - rata } & 77,82 & \\
\hline
\end{tabular}

Berdasarkan Tabel 8 terlihat bahwa rata-rata hasil belajar siswa pada materi satuan panjang adalah 72,61 termasuk cukup dengan KKM secara klasikal sebesar $14 / 23=60,86 \%$.

\section{KESIMPULAN}

Berdasarkan hasil pembahasan, dapat disimpulkan sebagai berikut (1) Terdapat peningkatan dalam menyusun rencana pembelajaran, dari siklus I sebesar 3,25 meningkat menjadi 3,63 pada siklus II, (2) Terdapat peningkatan dalam melaksanakan pembelajaran masing-masing siklus sebagai berikut; silkus I 
3,33 meningkat menjadi 4,04 pada siklus II. (3) Hasil Belajar siswa meningkat dari siklus I rata-rata sebesar 72,61 dengan KKM secara klasikal $=60,86 \%$ menjadi rata-rata 77,82 dengan KKM secara klasikal sebesar 19/23 =82,60\% .

\section{SARAN}

Adapun saran dari penelitian ini sebagai berikut: (1) Agar terdapat peningkatan profesionalisme guru dalam membuat desain (rancangan) pembelajaran diharapkan para tenaga kependidikan untuk lebih sering mengadakan supervisi yang bersifat Supervisi akademik ke dalam kelas, terutama para Pengawas Sekolah. (2) Agar profesionalisme guru dalam melaksanakan pembelajaran terdapat peningkatan, diharapkan para Pengawas Sekolah, maupun tenaga kependidikan yang lain sering melakukan Supervisi akademik kelas pada saat proses pembelajaran berlangsung.

\section{DAFTAR RUJUKAN}

Arikunto, Suharsimi. 2006. Prosedur Penelitian Suatu Pendekatan Praktik. Jakarta : Rineka Cipta.

Dimyati. 2010. Belajar dan Pembelajaran. Jakarta : Rineka Cipta.

Ekawarna. 2011. Penelitian Tindakan Kelas. Jakarta : Gaung Persada Press.

Iskandar. 2011. Penelitian Tindakan Kelas. Jakarta: Gaung Persada Press.

Kunandar. 2011. Langkah Mudah Penelitian Tindakan Kelas Sebagai Pengembangan Profesi Guru. Jakarta : PT Rajagrafindo Persada.

Lamijan, dkk.2007. Refleksi pendidikan masa kini. Surabaya: Fakultas ilmu pendidikan universitas negeri surabaya.

Misrianti, Feybian. 2015 . Wawancara Klinis Berbantuan Alat Peraga Untuk Mengatasi Kesulitan Siswa Dalam Materi Perbandingan Trigonometri Di SMA. Jurnal Penelitian Pendidikan (JPP) Volume III, No.4, April 2015 hlm 1-11.

Sudarno.2013. Tsubasa Meter. https://www.sekolahdasar.net/mediapembelajaran:tsubasa-meter/ diakses tanggal 10 November 2015

Sudjana, Nana. 2010. Dasar-dasar Proses Belajar Mengajar. Bandung : Sinar Baru Algensindo.

Ulfa, Nanik. 2013. Penggunaan Media Bangun Geometri untuk Menanamkan Konsep Penjumlahan Pecahan. Jurnal Pendidikan Sains (JPS) Volume I, No.3, September 2013 hlm 249-257.

Undang - Undang Nomor 20 Tahun 2003. 